\title{
Evaluation of the XpertMTB/RIF for the Diagnosis of Pulmonary Tuberculosis Among the Patients Attending DOTS Center Parsa District of Nepal
}

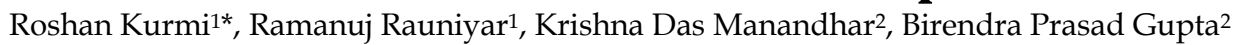

1Bhawani Hospital, Birgunj, Parsa, Nepal.

${ }^{2}$ Central Department of Biotechnology, Tribhuvan University, Kirtipur, Nepal.

\begin{abstract}
Tuberculosis diagnosis and monitoring rely in Sputum microscopy of National Tuberculosis Programme, Nepal because of its low cost and easier to perform. Direct sputum microscopy is popular worldwide. Currently, there are 533 microscopy centres catering for sputum microscopy examination throughout the country. Most of the microscopy centres are established within government jurisdiction and remaining are established as nongovernmental organization as well as private sectors.

A cross-sectional study was conducted from July 2013 to January 2015. A total of 2091 patients were enrolled in the study who were attending the DOTS Centre in Parsa District of Public Health Office, Nepal. Smears stained with ZN stain methods were examined microscopically followed by the GeneXpert MTB/RIF assay.

Out of 2091 suspected pulmonary TB patients enrolled for sputum microscopy and GeneXpert MTB/RIF for the confirmation of TB, the $1301(62.21 \%)$ were male and $790(37.78 \%)$ were female. The maximum TB cases were from Parsa district $(555,26.5 \%)$. The comparative study of different diagnostic tools reveals the sensitivity of MTB/RIF was $95.50 \%(91.87,97.82)$ and significantly higher than smear microscopy performed on the same fluid, which had a sensitivity of $61.97 \%(55.41,68.21)$. Five of 127 smear-negative cases had MTB/RIF-positive uncentrifuged sputum, resulting in a specificity of $81.23 \%(75.95,85.78)$, which was similar to smear microscopy $98.29 \%(97.34,98.97 ; \mathrm{p}=0.121)$. The positive predictive value (PPV) and negative predictive value (NPV) of MTB/RIF were $96.85 \%(93.61,98.72)$ and $94.95 \%(93.52,96.14)$, respectively. HIV co-infection did not impact sensitivity, specificity or liquid culture time to positivity (TTP). When MTB/RIF accuracy was evaluated using composite reference standard culture positivity from sputum, the sensitivity and specificity were similar to those obtained in the primary analysis using either definite TB versus possible and non-TB combined; definite and possible TB combined versus non-TB.
\end{abstract}

Keywords: Mycobacterium tuberculosis, Prevalence, GeneXpert, Nepal

*Corresponding Authors

E-mail: dr_roshankurmi@hotmail.com

\section{Introduction}

Tuberculosis (TB) is a leading cause of death worldwide. In the early 1990s, the government of Nepal brought up a program to control TB at national scale called DOTS (Directly Observed Treatment Short Course) [1]. DOTS program was initiated in April 2001 with a goal to diagnose and cure TB patients which has treated more than 20 thousand patients till date [2]. Until December of 2014 there are 554 microscopy centres and 22 GenXpert location in the country which specializes in diagnosis of TB [3]. The expansion of DOTS program has proven its efficacy in reducing the mortality and morbidity in Nepal, however, despite of available diagnosis and treatment regimes, approximately 3000-5000 people are still dying per year of TB [4]. In a DOTS centre in Kathmandu, prevalence of Multi Drug Resistant
(MDR) case of Tuberculosis was found to be 3.6\% [5], which could have been mitigated by early diagnosis and rapid identification of anti-TB agents resistance. Recent data from East Nepal suggests that $3.3 \%$ of all patients, who were smear microscopy negative, have RMP resistant TB [6]. Despite of DOTS and available diagnosis, complications due to MDR are emerging and also there hasn't been overall increment in number of people on anti tuberculosis treatment [6]. Sputum smear light microscopy, patients symptoms combined with CXR results is the preferred algorithm for TB diagnosis in Nepal. Smear test is neither relevant nor sensitive enough for the diagnosis of TB alone and needs additional diagnosis as well clinical suspecting to decide either patients should be enrolled on antibiotic or not [7]. 
This study aims to clarify if current algorithm of TB diagnosis is flexible enough to trace the TB rates at GeneXpert centre in Parsa district of Public Health Office, Nepal. Our aims were to determine epidemiological characteristics, HIV status of patients with tuberculosis and comparative study of different test routinely used for diagnosis of TB at a large outpatient clinic in Parsa of Nepal.

\section{Materials and Methods Study sites and population}

Study was conducted in Parsa district in the Narayani Zone of southern Nepal which lies $283 \mathrm{~km}(176 \mathrm{mi})$ south of the capital Kathmandu, $3 \mathrm{~km}$ north of the border of the Indian state of Bihar with population 315,011 in 2011. The district is divided into 86 Village Development Committees and one municipality which is one of the relatively well developed districts in the country located on the flat Terai lowland. The public health sector has 49 facilities including 1 zonal hospital, 1 public health office, 3 primary health centres, 9 health posts and 35 sub-health posts, additionally there are 6 private sector facilities thus resulting in a total of 55 facilities providing DOTS services in Parsa district. The reported notification rate of new pulmonary positive tuberculosis in Parsa district was 69 per 100,000 populations in 2014 [3].

\section{Patient classification and diagnosis algorithm}

Patients with suspected TB ( $\geq 18$ ye of age) were enrolled between April 2014 and May 2015. WHO algorithm was basis for the classification of suspects of TB. Based on WHO algorithm, two subgroups were formed to classify TB suspects; 1 ) patients with cough for $\geq 2$ weeks and 2) patients without cough for $\geq 2$ weeks but having symptoms like weight loss accompanied with night fever $\mathrm{T}>37.5^{\circ} \mathrm{C}$, pleural effusion or pericarditis induced breathlessness, chronic headache, swelled armpit $(>2 \mathrm{~cm})$ or abnormal chest radiogram, thus referred as, "with cough or without cough". Patients with WHO defined danger sign with respiratory rate $>30$ / minute, fever $>39^{\circ} \mathrm{C}$, pulse rate $>120 /$ minute and unambulatory patients were excluded from the study.

Smear positive were not enrolled for GenXpert thus were directly enrolled for anti TB regime.
Remaining patients with smear negative were enrolled in GenXpert and further confirmation was done by liquid culture for MTB positive and RIF resistant samples. Those cultures were further screened for MDR against first line and second line drugs.

Patients with sputum negative for $\mathrm{TB}$ were classified as possible TB (if they are on anti-TB treatment program) or as non-TB (if they are not on anti-TB treatment program). Prospective patients ( $\geq 20$ years of age) with suspected pulmonary TB $(n=2091)$ were enrolled in the study who were attending the DOTS Centre in Parsa District of Public Health Office, Nepal from Jul 2013 to Jan 2015. Patients had at least one symptom of TB including chest radiograph with infiltrates and smear microscopy negative results in duplicate.

\section{Specimen collection and laboratory procedures}

Sputum specimens were processed using standardized protocols. The length of time between sample collection and results being issued to the clinic was also recorded. Smears stained with $\mathrm{ZN}$ stain methods were examined microscopically following the standard protocol. At least 200 fields were evaluated before reporting negative. Bacillary density was graded as scanty, $1+, 2+$, and $3+$, and all such smears were defined as "smear-positive'. Following decontamination with N-acetyl-Lcysteine and sodium hydroxide, centrifuged sputum deposits underwent microscopy, and following re-suspension in phosphate buffer, equal volumes were tested by the GeneXpert MTB/RIF assay. The results of all tests were read by technologists blinded to the outcomes of the other assays. Sputum pellets were also tested by trained technologists using the GeneXpert MTB/RIF assay.

\section{GeneXpert MTB/RIF and patient management}

The collected sputum sample was aliquoted in two equal volumes; first half for immediate primary clinical works and other for reference for future works at $-20^{\circ} \mathrm{C}$. From the first aliquot, the specimen was used for smear tests followed by GeneXpert MTB/RIF assay. The diagnostic assays were followed by a single specialized clinical research associate blind to the patient's diagnosis in 
Table 4: Clinical Feature of Tuberculosis

\begin{tabular}{ccc}
\hline Clinical Feature & Present & Absent \\
\hline Fever & 1885 & 206 \\
Cough & 1741 & 350 \\
Weight Loss & 1471 & 620 \\
Night sweat & 1655 & 436 \\
Loss of appetite & 1376 & 715 \\
Malaise & 1117 & 974 \\
Chest Pain & 1744 & 347
\end{tabular}

reference standard and index test, throughout the study period.

\section{Statistical analysis}

Collected data were analyzed and interpreted statistically using graphPad prism version 6.0 and SPSS 17.0. All the values are expressed as mean \pm SD and are analyzed using Student's $t$ test which is parametric as well Mann-Whitney test wherever applicable. $\mathrm{P}$ value $(\mathrm{P}<0.05)$, was considered significant unless stated otherwise.

\section{Results}

\section{Study population and TB diagnoses}

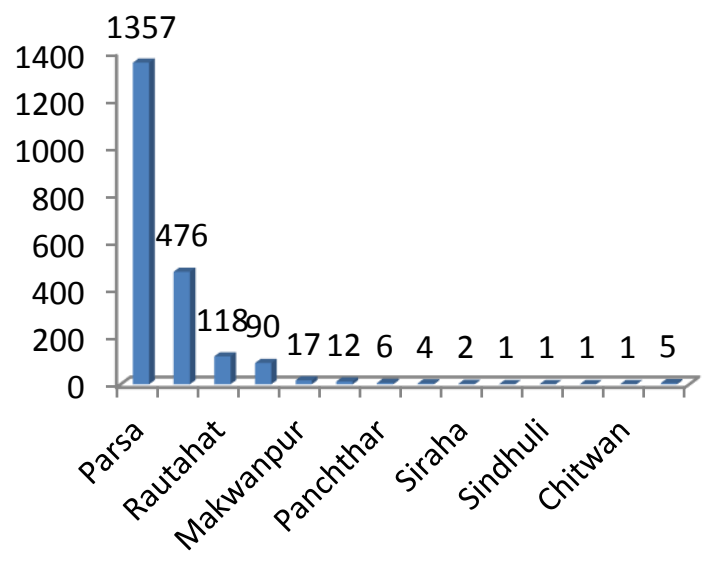

Figure 1: District wise number of Tuberculosis Patients visited at GeneXpert Centre in Parsa

The suspected pulmonary TB patients $(n=2091)$ were enrolled for sputum microscopy and GeneXpert MTB/RIF for the confirmation of TB. Among them, 1301(62.21\%) were male and 790 $(37.78 \%)$ were female. All the patients were referred to this centre by local doctors and physicians after having tuberculosis symptoms and abnormal chest radiograph for sputum microscopy and GeneXpert MTB/RIF for the confirmation of Makwanpur, Mahottari, Panchthar, Saptari, Siraha, Morang, Sindhuli, Rasuwa and Chitwan (Figure 1). Since the study conducted at Parsa district, the actual number of case presented here does not highlight the prevalence of $\mathrm{TB}$ in the respective district.

As Bara is the adjacent district to Parsa, the number of patients visited is more than other district. The prevalence of TB in Parsa district is 3 times higher than the prevalence in the Bara district.

TB. The clinical symptoms showed most of the patients have fever, cough, and weight loss and night sweat (Table 4).

The maximum TB cases were from Parsa district (555, 26.5\%) followed by Bara, Rautahat, Sarlahi,

\section{Diagnostic accuracy of different method and MTB/RIF performed on un- centrifuged sputum}

Direct sputum microscopy is popular worldwide. In Nepal, the Tuberculosis diagnosis and monitoring rely in Sputum microscopy because of its low cost and easier to perform. At present there are 533 microscopy centres catering the sputum microscopy examination throughout the country. The region wise distribution is given in Table $\mathbf{1}$. Most of the microscopy centres are established in government setting and few are established in nongovernmental organization and private sectors. NTC-National

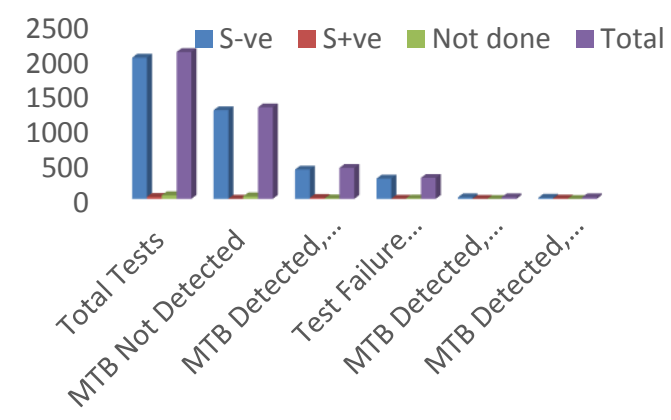

Figure 2: MDR Pattern in TB Patients

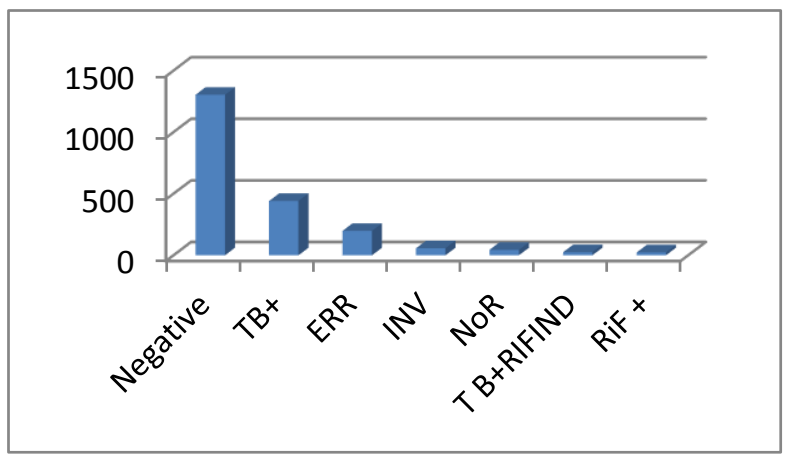

Figure 3: Gene Xpert MTB RIF Pattern in TB patient 
Reference Laboratory and GENETUP are providing culture and in the beginning of 2012, a new molecular diagnostic tool; Gene Xpert MTB/RIF machines for rapid diagnosis of DR TB had been introduced to nine health facilities (7 in Eastern Region and 2 in Central Region) in collaboration with NTP Nepal and International Organization for Migration (IOM) through TB Reach funding. Gene Xpert MTB RIF Pattern in TB patient and MDR Pattern in TB Patients are shown in Figure 2 and Figure 3 respectively.

Table 1: Number of DOTS and Microscopy Centres by Region

\begin{tabular}{|c|c|c|c|c|c|c|}
\hline $\begin{array}{l}\text { Development } \\
\text { Region/ } \\
\text { Centres }\end{array}$ & EDR & CDR & $\begin{array}{l}\text { WD } \\
\mathrm{R}\end{array}$ & $\begin{array}{l}\text { MWD } \\
\text { R }\end{array}$ & $\begin{array}{l}\text { FW } \\
\text { DR }\end{array}$ & Total \\
\hline $\begin{array}{l}\text { No. of } \\
\text { treatment } \\
\text { centres }\end{array}$ & 237 & 366 & 239 & 199 & 143 & 1184 \\
\hline $\begin{array}{l}\text { No. of Sub- } \\
\text { centres }\end{array}$ & 709 & 1008 & 667 & 406 & 284 & 3074 \\
\hline DR $\quad$ TB & 2 & 4 & 3 & 1 & 3 & 13 \\
\hline \multicolumn{7}{|l|}{$\begin{array}{l}\text { Treatment } \\
\text { centres }\end{array}$} \\
\hline DR $\quad$ TB & 11 & 37 & 15 & 5 & 3 & 71 \\
\hline \multicolumn{7}{|l|}{$\begin{array}{l}\text { Treatment } \\
\text { sub-centres }\end{array}$} \\
\hline $\begin{array}{l}\text { Microscopy } \\
\text { centres }\end{array}$ & 122 & 198 & 82 & 73 & 79 & 554 \\
\hline \multirow{2}{*}{\multicolumn{7}{|c|}{$\begin{array}{l}\text { * Showed the number of DOTS and Microscopy centres in whicl } \\
\text { number of sub-centres are more followed by number } \\
\text { treatment centres and microscopy centres. There is few DR Th } \\
\text { treatment centres. (EDR: Eastern Development Region. CDR } \\
\text { Central Development Region; WDR: Western Developmen } \\
\text { Region; MWDR: Mid Western Development Region; FWDR: Fa } \\
\text { Western Development Region) } \\
\text { Table 3: Comparison of different test for diagnosis of } \\
\text { pulmonary Tuberculosis }\end{array}$}} \\
\hline & & & & & & \\
\hline \multicolumn{3}{|c|}{ Test } & \multicolumn{4}{|c|}{ Result } \\
\hline \multicolumn{3}{|c|}{ Smear Positive } & \multicolumn{4}{|c|}{585} \\
\hline \multicolumn{3}{|c|}{ Smear Negative } & \multicolumn{4}{|c|}{1506} \\
\hline \multicolumn{3}{|c|}{ Gene Xpert Positive } & \multicolumn{4}{|c|}{788} \\
\hline \multicolumn{3}{|c|}{ Gene Xpert Negative } & \multicolumn{4}{|c|}{1303} \\
\hline
\end{tabular}

The comparative study of different diagnostic tools is given in Table 3 .

Of the 2091 patients enrolled in this study, the sensitivity of MTB/RIF was 95.50\% (91.87, 97.82) and significantly higher than smear microscopy performed on the same fluid, which had a sensitivity of $61.97 \%$ (55.41, 68.21, Table 5). Five of 127 smear-negative cases had MTB/RIF-positive un-centrifuged sputum, resulting in a specificity of $81.23 \%(75.95,85.78)$, which was similar to smear microscopy $98.29 \%(97.34,98.97 ; p=0.121)$. The positive predictive value (PPV) and negative predictive value (NPV) of MTB/RIF were 96.85\% (93.61, 98.72) and $94.95 \%$ (93.52, 96.14), respectively. HIV co-infection did not impact sensitivity, specificity (Table 6) or TTP. When MTB/RIF accuracy was evaluated using composite reference standard culture positivity from sputum, the sensitivity and specificity were similar to those obtained in the primary analysis using either definite TB versus possible and non-TB combined; definite and possible TB combined versus non-TB.

\section{Discussion}

In Nepal, the estimated incidence of TB is 163 per 100,000 with a prevalence rate of 241 per 100,000 populations. In 2014-15, the Nepal Tuberculosis Programme (NTP) registered 17,788 sputum smearpositive cases and 8,367 sputum smear negative cases [6, 8]. A total of 2091 individuals from thirteen districts of Nepal were included in the present study and the prevalence of smear positive pulmonary tuberculosis was found to be 788 out of 2091(37.06 \%). We found the most of the patients were passively participated in the study and almost all patients are visited Government hospital for the treatment. Approximately $66.76 \%$ of the patient had the cough duration for last 2 days. Although, only $37.09 \%$ of patients had AFB positive on smear, out of which $97.8 \%$ were new

Table 5: Pattern of sputum culture with active TB

\begin{tabular}{|c|c|c|c|}
\hline Parameters & $\begin{array}{l}\text { Cohort } \\
(\mathrm{n}=2091)\end{array}$ & $\begin{array}{lr}\text { Sputum } & \text { smear } \\
\text { positive } & \text { with } \\
\text { active TB } & \\
(n=672) & \end{array}$ & $\begin{array}{lr}\text { Sputum } & \text { smear } \\
\text { negative } & \\
\text { compatible } & \text { with } \\
\text { active } & \text { TB } \\
(\mathrm{n}=1419) & \end{array}$ \\
\hline $\begin{array}{l}\text { Median age in } \\
\text { years }\end{array}$ & $\begin{array}{c}37.3(26.1- \\
48.3)\end{array}$ & $\begin{array}{c}33.8(28.1- \\
42.8)\end{array}$ & $37.4(29.9-47.1)$ \\
\hline Male & 1301 & 464 & 725 \\
\hline Female & 790 & 208 & 694 \\
\hline HIV infected & 65 & 22 & 43 \\
\hline $\begin{array}{l}\text { Median CD4 } \\
\text { counts (If HIV } \\
\text { positive) }\end{array}$ & 98 & 78 & 20 \\
\hline $\begin{array}{l}\text { Previous } \\
\text { treatment }\end{array}$ & 89 & 9 & 80 \\
\hline $\begin{array}{l}\text { Smokers (Past } \\
\text { or current) }\end{array}$ & 201 & 118 & 83 \\
\hline
\end{tabular}


cases and only 2.2. \% is repeated cases; the Chest $X$ ray reveals $99.43 \%$ had abnormal finding in chest. The GeneXpert result shows large number of patients diagnosed with Tuberculosis. This might be that the AFB is not present in initial few days because most of the patient has visited less than 5 days of appearance of cough. The similar study carried by Shagufta Iram et al[9], shows the GeneXpert MTB/RIF is a sensitive method for rapid diagnosis of Tuberculosis, especially in smear negative cases and in PTB as compared to the conventional ZN staining. For countries endemic for TB GeneXpert can serve as a sensitive and time saving diagnostic modality for pulmonary TB. Our study is consistent with other studies which have suggested the benefit of GeneXpert in smearnegative patients in developing countries [10, 11].The majority of these studies have been carried out in Africa where there is a substantially higher
HIV burden than in South Asia. Three studies have been reported from low-HIV prevalence regions, including Peru and two hospitals (Hinduja Hospital and Christian Medical College Hospital) in India $[11,12]$.

It is not clear how many of the patients testing positive for MTB by smear, culture and Gene Xpert in this study would have been started on TB treatment based on the judgement of the treating clinician if GeneXpert testing was not available. In the previous year (2013-2014) at Parsa district, 2245 patients were treated for $\mathrm{TB}$, approximately onethird of those detected by GeneXpert during the study period. It is possible that the availability of GeneXpert increased the recognition of TB symptoms, although we can claim that in this endemic setting TB awareness is consistently high among clinicians. Conversely, it is possible that a negative smear test may have discouraged

Table 6: Accuracy of Xpert MTB/RIF for the detection of Smear positive TB in sputum

\begin{tabular}{|c|c|c|c|c|c|c|}
\hline & $\begin{array}{l}\text { All patients } \\
\mathbf{n = 2 0 9 1} \\
\text { Sensitivity, \% } \\
(95 \% \mathrm{CI})\end{array}$ & $\begin{array}{l}\text { Specificity, \% } \\
(95 \% \mathrm{CI})\end{array}$ & $\begin{array}{l}\text { HIV uninfected } \\
\mathbf{n = 2 0 2 6} \\
\text { Sensitivity, \% } \\
(95 \% \mathrm{CI})\end{array}$ & $\begin{array}{l}\text { Specificity, \% } \\
(95 \% \mathrm{CI})\end{array}$ & $\begin{array}{c}\text { HIV infected } \\
\mathbf{n}=\mathbf{6 5} \\
\text { Sensitivity, \% } \\
(95 \% \mathrm{CI})\end{array}$ & $\begin{array}{l}\text { Specificity, } \\
\%(95 \% \text { CI) }\end{array}$ \\
\hline Smear microscopy & $\begin{array}{c}61.97 \% \\
(55.41,68.21)\end{array}$ & $\begin{array}{c}96.48 \%(95.24, \\
97.48)\end{array}$ & $\begin{array}{c}78.38 \% \\
(71.74,84.08)\end{array}$ & $\begin{array}{c}92.50 \% \\
(90.85,93.93)\end{array}$ & $\begin{array}{c}62.36 \% \\
(51.93,64.82)\end{array}$ & $\begin{array}{c}95.23 \% \\
(93.84,97.41)\end{array}$ \\
\hline $\begin{array}{c}\text { MTB/RIF } \\
\text { performed on } \\
\text { uncentrifuged }\end{array}$ & $\begin{array}{c}95.50 \% \\
(91.87,97.82)\end{array}$ & $\begin{array}{c}94.69 \% \\
(93.23,95.92)\end{array}$ & $\begin{array}{c}77.66 \% \\
(72.24,82.46)\end{array}$ & $\begin{array}{c}99.09 \% \\
(98.33,99.56)\end{array}$ & $\begin{array}{c}94.13 \% \\
(90.16,95.28)\end{array}$ & $\begin{array}{c}92.47 \% \\
(90.67,94.54)\end{array}$ \\
\hline $\begin{array}{c}\text { MTB/RIF } \\
\text { performed on } \\
\text { uncentrifuged }\end{array}$ & $\begin{array}{c}81.23 \% \\
(75.95,85.78)\end{array}$ & $\begin{array}{c}98.29 \% \\
(97.34,98.97)\end{array}$ & $\begin{array}{c}91.77 \% \\
(87.45,94.98)\end{array}$ & $\begin{array}{c}95.70 \% \\
(94.36,96.80)\end{array}$ & $\begin{array}{c}83.82 \% \\
(76.72,86.26)\end{array}$ & $\begin{array}{c}94.78 \% \\
(91.23,97.76)\end{array}$ \\
\hline $\begin{array}{c}\text { sputum in patients } \\
\text { who were smear } \\
\text { negative }\end{array}$ & & & & & & \\
\hline \multirow{2}{*}{$\begin{array}{l}\text { MTB/RIF } \\
\text { performed on a } \\
\text { resuspended pellet } \\
\text { of centrifuged } \\
\text { sputum }\end{array}$} & $\begin{array}{c}51.89 \% \\
(44.94,58.78)\end{array}$ & $\begin{array}{c}93.79 \% \\
(92.24,95.11)\end{array}$ & $\begin{array}{c}60.44 \% \\
(52.94,67.60)\end{array}$ & $\begin{array}{c}91.42 \% \\
(89.68,92.95)\end{array}$ & $\begin{array}{c}52.62 \% \\
(46.73,56.28)\end{array}$ & $\begin{array}{c}91.72 \% \\
(89.91,93.63)\end{array}$ \\
\hline & $\begin{array}{c}\text { PPV† } \\
(95 \% \mathrm{CI})\end{array}$ & $\begin{array}{c}\text { NPV† } \\
(95 \% \mathrm{CI})\end{array}$ & $\begin{array}{c}\text { PPV† } \\
(95 \% \text { CI })\end{array}$ & $\begin{array}{c}\text { NPV† } \\
(95 \% \mathrm{CI})\end{array}$ & $\begin{array}{c}\text { PPV† } \\
(95 \% \text { CI })\end{array}$ & $\begin{array}{c}\text { NPV† } \\
(95 \% \mathrm{CI})\end{array}$ \\
\hline Smear microscopy & $\begin{array}{c}47.44 \% \\
(40.61,54.34)\end{array}$ & $\begin{array}{c}92.73 \% \\
(91.08,94.16)\end{array}$ & $\begin{array}{c}54.84 \% \\
(47.39,62.13)\end{array}$ & $\begin{array}{c}90.46 \% \\
(88.65,92.08)\end{array}$ & $\begin{array}{c}85.95 \% \\
(80.92,90.07)\end{array}$ & $\begin{array}{c}98.76 \% \\
(97.93,99.32)\end{array}$ \\
\hline $\begin{array}{l}\text { MTB/RIF } \\
\text { performed on } \\
\text { uncentrifuged } \\
\text { sputum }\end{array}$ & $\begin{array}{c}96.85 \% \\
(93.61,98.72)\end{array}$ & $\begin{array}{c}94.95 \% \\
(93.52,96.14)\end{array}$ & $\begin{array}{c}78.75 \% \\
(73.42,83.45)\end{array}$ & $\begin{array}{c}99.36 \% \\
(98.69,99.74)\end{array}$ & $\begin{array}{c}93.69 \% \\
(89.65,96.51)\end{array}$ & $\begin{array}{c}97.04 \% \\
(95.89,97.94)\end{array}$ \\
\hline $\begin{array}{c}\text { MTB/RIF } \\
\text { performed on } \\
\text { uncentrifuged } \\
\text { sputum in patients } \\
\text { who were smear } \\
\text { negative }\end{array}$ & $\begin{array}{c}62.61 \% \\
(56.12,68.77)\end{array}$ & $\begin{array}{c}97.09 \% \\
(95.93,97.99)\end{array}$ & $\begin{array}{c}81.87 \% \\
(75.49,87.18)\end{array}$ & $\begin{array}{c}92.51 \% \\
(90.87,93.95)\end{array}$ & $\begin{array}{c}51.89 \% \\
(44.94,58.78)\end{array}$ & $\begin{array}{c}94.48 \% \\
(93.00,95.72)\end{array}$ \\
\hline $\begin{array}{c}\text { MTB/RIF } \\
\text { performed on a } \\
\text { resuspended pellet } \\
\text { of centrifuged } \\
\text { sputum }\end{array}$ & $\begin{array}{c}47.44 \% \\
(40.61,54.34)\end{array}$ & $\begin{array}{c}92.73 \% \\
(91.08,94.16)\end{array}$ & $\begin{array}{c}54.84 \% \\
(47.39,62.13)\end{array}$ & $\begin{array}{c}90.46 \% \\
(88.65,92.08)\end{array}$ & $\begin{array}{c}90.13 \% \\
(87.25,92.47)\end{array}$ & $\begin{array}{c}52.43 \% \\
(49.10,53.91)\end{array}$ \\
\hline
\end{tabular}


treatment in some cases which would otherwise have been treated, although clinicians were informed that a negative smear test does not exclude a TB diagnosis. Patients with a strong possibility of pulmonary TB despite a negative smear test were referred for further investigations including culture at a tertiary centre. The rate of smear positivity at Parsa is $15.0 \%$ which is consistent with the results in other areas of similar endemicity; it is therefore unlikely that the GeneXpert diagnosis was inflated due to low smear microscopy confirmation [13-15].

If we look on test selection, smear microscopy, due to its simplicity, speed, and low cost, is used widely in low-resource settings; the low sensitivity precludes it from being an ideal test. The requirement for a rapid, simple TB diagnostic is evidenced by the widespread application of commercial serological tests which are inaccurate. These tests are widely provided at a cost to the patient and used to determine medical treatment.

Although the GeneXpert has several limitations, including requirement for stable electricity supply, limited temperature range, availability of maintenance, and bulky consumables, wider availability of the accurate GeneXpert assay may counter the use of these serological tests by providing a viable alternative to the patient and healthcare provider. It is highly probable that a small number of cases of TB were missed in this study as GeneXpert does not have as high sensitivity as culture. There is a danger that clinicians will "exclude" a TB diagnosis on the basis of a negative GeneXpert test and it is important that education is carried out to ensure clinicians are aware of the test limitations prior to the test being implemented. However, it is not sustainable to implement TB culture facilities at general hospitals in South Asia and the long turnaround of results means loss to follow-up in the diagnostic pathway is high. This study was not an assessment of GeneXpert sensitivity and specificity, as this has been comprehensively evaluated in comparison with culture by others.

\section{Conclusion}

The prevalence of TB is high in Parsa DOTS centre in comparable to other districts of Nepal. However, the relatively higher rate of RIF resistance observed in our study signals the danger of increasing MDRTB in the study areas in the future in Nepal. On the other hand, MTB RIF positivity among sputum negative, RIF resistant (DR TB) among sputum negative and RIF resistant among retreatment cases is large in this study. The higher level of MDR-TB among previously treated patients suggests the need to strengthen the DOTS strategy and the capacity of laboratories to undertake effective treatment especially among previously treated patients in Nepal. The GeneXpet is more specific and sensitive that smear AFB detection. The Government of Nepal Ministry of Health and population should implement GeneXpert in each DOTS centre in Nepal for better diagnosis.

\section{Abbreviations}

CXR: Chest X-Ray; DOTS: Directly observed treatment short course; DST: Drug susceptibility testing; HIV: Human Immunodeficiency Virus; MDR: Multidrug-resistance; NTP: National Tuberculosis Program; PPV: Positive Predictive Value; NPV: Negative Predictive Value.

\section{Authors' contributions}

RK, BPG was involved in the study conception and design, data analysis and drafting of the manuscript. AA, RR and KDM were involved in the design and reviewing of the manuscript. BPG was involved in reviewing of the manuscript. All authors have read and approved the final version of the manuscript.

\section{Conflict of Interests}

The authors declare no competing interests regarding the publication of this paper.

\section{Acknowledgment}

Authors acknowledge the role of the staff of DOTS Centre, Parsa during the conduct of this study for their invaluable help during the identification of cases and collection of data.

\section{References}

1. His Majesty's Government of Nepal Ministry of Health and the World Health Organization. Tuberculosis Control in Nepal 1995-1999. A development plan for the National Tuberculosis Programme. Kathmandu, Nepal, 1995.

2. National Tuberculosis Programme. Tuberculosis control in Nepal. Status report. Thimi, Nepal: National Tuberculosis Centre. 1997. 
3. Goverment of Nepal. National Tuberculosis Center 2014. http://www.nepalntp.gov.np/ index.php?view $=$ publication

4.

5. Bhatt $\mathrm{CP}$, Bhatt $\mathrm{AB}$, Shrestha $\mathrm{B}$ : Drug resistant cases of tuberculosis in directly observed treatment short course. Journal of Nepal Health Research Council 2010, 8(1):44-47.

6. Creswell J, Rai B, Wali R, Sudrungrot $S$, Adhikari LM, Pant R, Pyakurel S, Uranw D, Codlin AJ: Introducing new tuberculosis diagnostics: the impact of Xpert((R)) MTB/RIF testing on case notifications in Nepal. The international journal of tuberculosis and lung disease: the official journal of the International Union against Tuberculosis and Lung Disease 2015, 19(5):545-551.

7. Desikan P: Sputum smear microscopy in tuberculosis: is it still relevant? The Indian journal of medical research 2013, 137(3):442-444.

8. Banjara MR, Kroeger A, Huda MM, Kumar V, Gurung CK, Das ML, Rijal S, Das P, Mondal D: Feasibility of a combined camp approach for vector control together with active case detection of visceral leishmaniasis, post kala-azar dermal leishmaniasis, tuberculosis, leprosy and malaria in Bangladesh, India and Nepal: an exploratory study. Transactions of the Royal Society of Tropical Medicine and Hygiene 2015, 109(6):408-415.

9. Iram $S$, Zeenat $A$, Hussain $S$, Wasim Yusuf $N$, Aslam M: Rapid diagnosis of tuberculosis using Xpert MTB/RIF assay - Report from a developing country. Pakistan journal of medical sciences 2015, 31(1):105-110.

10. Rachow A, Zumla A, Heinrich N, Rojas-Ponce G, Mtafya B, Reither K, Ntinginya EN, O'Grady J, Huggett J, Dheda $\mathrm{K}$ et al: Rapid and accurate detection of Mycobacterium tuberculosis in sputum samples by Cepheid Xpert MTB/RIF assay--a clinical validation study. PloS one 2011, 6(6):e20458.

11. Boehme CC, Nicol MP, Nabeta P, Michael JS, Gotuzzo E, Tahirli R, Gler MT, Blakemore R, Worodria W, Gray C et al: Feasibility, diagnostic accuracy, and effectiveness of decentralised use of the Xpert MTB/RIF test for diagnosis of tuberculosis and multidrug resistance: a multicentre implementation study. Lancet 2011, 377(9776):1495-1505.

12. Vassall A, van Kampen S, Sohn H, Michael JS, John KR, den Boon S, Davis JL, Whitelaw A, Nicol MP, Gler MT et al: Rapid diagnosis of tuberculosis with the Xpert MTB/RIF assay in high burden countries: a cost-effectiveness analysis. PLOS medicine 2011, 8(11):e1001120.

13. Hamid S, Hussain SA, Ali I: Comparative analysis of case screening with varying cough duration and sputum samples for diagnosis of tuberculosis in patients attending the OPD at a tertiary care hospital at Srinagar, India. Nigerian journal of clinical practice 2012, 15(4):430-435.
14. Malhotra S, Zodpey SP, Chandra S, Vashist RP, Satyanaryana S, Zachariah R, Harries AD: Should sputum smear examination be carried out at the end of the intensive phase and end of treatment in sputum smear negative pulmonary TB patients? PloS one 2012, 7(11):e49238.

15. Hooja S, Pal N, Malhotra B, Goyal S, Kumar V, Vyas L: Comparison of Ziehl Neelsen \& Auramine $O$ staining methods on direct and concentrated smears in clinical specimens. The Indian journal of tuberculosis 2011, 58(2):72-76. 